Research Article

\title{
Variation in Amino Acid Contents in Chickpea Cultivars in Response to Ascochyta rabiei Infection
}

\author{
Muhammad Usman Ghazanfar ${ }^{1}$, Waqas Wakil ${ }^{2}$, Shahbaz Talib Sahi ${ }^{3}$, Waqas Raza $^{1 *}$ and Mahmood Ahmad \\ Randhawa $^{4}$
}

${ }^{1}$ College of Agriculture, University of Sargodha, Sargodha 40100, Pakistan; 2 Department of Entomology, University of Agriculture, Faisalabad 38000, Pakistan; ${ }^{3}$ Department of Plant Pathology, University of Agriculture, Faisalabad 38000, Pakistan; ${ }^{4}$ Department of Continuing Education, University of Agriculture, Faisalabad 38000, Pakistan.

Abstract | The metabolic changes that took place during host-pathogen interaction have been poorly
investigated. Although photosynthesis disturbance and carbon metabolism re-programming have been
studied yet, there is scary of data on plant amino acids after induction of resistance. Here we investigated
the amino acid contents in induced and un-inoculated and invaded region after induction of resistance. The
quantities of methionine, iso-leucine, leucine, tyrosine and phenylalanine contents in three (Pb-91, C-44 and
Bittle-98) chickpea cultivars increased after induction and stress of $A$. rabiei and comparatively higher than
induced unstressed plants. The increase was more evident in case of Bion treatment as compared to all other
treatments with SA and KOH. Similar trend was shown by plant extracts where in neem extract induced
higher amino acid contents. The cultivar C-44 responds efficiently as compared with other two cultivars. The
results of the current study showed that amino acids play significant role in resistance and susceptibility of
chickpea cultivars against $A$. rabiei.
Received $\mid$ May 21, 2020; Accepted | March 29,2021; Published | June 01,2021
*Correspondence | Waqas Raza, College of Agriculture, University of Sargodha, Sargodha 40100, Pakistan; Email: waqasraza61@yahoo.com
Citation | Ghazanfar, M.U., W. Wakil, S.T. Sahi, W. Raza, M.A. Randhawa. 2021. Variation in amino acid contents in chickpea cultivars in
response to Ascochyta rabiei infection. Sarbad Journal of Agriculture, 37(2): $650-665$.
DOI $\mid$ http://dx.doi.org/10.17582/journal.sja/2021/37.2.650.665
Keywords | Chickpea, Ascochyta rabiei (Pass) Labr, Induce resistance, Resistant vs susceptible cultivars, Amino acid contents.

\section{Introduction}

$\mathrm{P}$ lant Pathologists continued to face immense challenges ahead because of ongoing problems of collapse of host resistance and fungicide insensitivity; furthermore, there is a threat of global climate change, its impact on the pathogen spread and the escalating human population worldwide (Walter et al., 2005). Plant Pathologists should be one step ahead of the pathogen, by understanding host-pathogen interaction, providing the means to protect crops (Walters and Fountaine, 2009). In this perspective, biotechnology's application can be a better alternative to reduce disease incidence (Lyon and Newton, 1999). Improvement and induction of the plant's defense mechanism relatively than the toxic compounds would be better choice to induced disease resistance from different plant pathogens (Van Wees et al., 1997) further preferred due to the reason that it activates the natural defense system of the host. So, chances of resistance development are less and its affectivity remains for longer period of time (Kuc, 2001).

Current study can untie lot of complex biochemical interactions between the host and its pathogens through broad range of mechanisms which may be systemic or local. The induced is the stimulus of 
natural defense systems of plants by the application of biological agent of chemicals (inducers) that are compatible with the environment (Altamiranda et al., 2008). They don't have the ability to produce the identical responses and it may differ with respect to host-pathogen contact (Gozzo, 2003). The induced resistance is not due to just antimicrobial agents but diverse mechanisms might be involved ('cascade' of induced responses) (Ryals et al., 1996). The different compounds e.g. reactive oxygen species, calcium, polyphenol oxidases, phytoalexins, thionins, proteases, callose and lignin, which help in strengthening of cell wall due to its deposition, polymer, lipoxygenases and phospholipases are synthesize and accumulate which may lead to resistance after the infection of pathogen (Kessman et al., 1994; Hutcheson, 1998). Resistance factors are induced only when host recognizes prevalence of potential pathogen and the different compounds able of triggering such responses are termed as elicitors. Application of salicylic acid, Bion, Potassium hydroxide (KOH) and extracts e.g., neem, garlic, datura encourage systemic resistance into different host pathogen contact by enhancing their defence mechanism by releasing different enzymes, peroxidases, chitinases, $\beta-1,3$-glucanases etc. (Paul and Sharma, 2002; Sarwar et al., 2005; Ajay and Baby, 2009: Boava et al., 2009). It has been reported that some Pathogenesis-related $(\mathrm{PR})$ proteins have chitinase (PR-2) group and $\beta-1,3$-glucanases (PR3 group) activity in-vitro (Mauch et al., 1988). These hydrolytic enzymes capable to degrading polysaccharides, chitin and $\beta-1,3$-glucan, so inhibit the fungal growth (Roulin and Buchala, 1995).

Chickpea blight caused by Ascochyta rabiei (Pass) Labr is most significant plant disease which upsets production statistics of this crop in the country (Kadiri et al., 2019; Moore et al., 2015). Under environmental conditions conducive to the development of disease epidemics of disease may be encountered causing 50\%-70\% crop losses (Sharma and Ghosh, 2016). The disease in practice may managed by the use of disease resistance seed (Motagi et al., 2020), destruction of plant debris (Davidson and Kimber, 2007), foliar and seed dressing chemicals (Vafaei et al.,2015; Ejeta et al., 2017) and plant host resistance (Ahmad et al., 2006; Malik et al., 2006; Zhou et al., 2019). Since various bio-chemical factors like phytoalexins (Komives and Kiraly, 2019), phenolic compounds (Gillmeister et al., 2019), amino acids (Sun et al., 2019) and minerals contribute (Cheng et al., 2020) to resistance of host plants against their pathogens. Lots of information regarding the role of different biochemical substance in resistance against $A$. rabiei are available like Sarwar et al. (2001) reported maximum PAL activity was record 12 24 $\mathrm{h}$ after inoculation in the resistant chickpea cultivar, while it took about 5 9 days in the susceptible cultivar yet very few reports are available on the role of induced resistance in chickpea against A. rabiei and its effect on biochemical factors of induced plant. Chaudhry et al. (2001) reported that total phenolic contents and peroxidase activity was improved in treated plants with (SA) salicylic acid, dipotssium hydrogen phosphate, cuprous chloride as compared to control. The objective of present study was to elucidate the changes in amino acids after induction of resistance with chemicals and plant extracts under $A$. rabiei stressed field conditions.

\section{Materials and Methods}

Chickpea cultivars (C-44-Pb-91-Bittle-98) that showed vulnerable response to $A$. rabiei (Ghazanfar et al.,2010a) but showed good yield potential (Ghazanfar et al., 2010b) were cultivated in field conditions in small plots of size $6.0 \mathrm{~m}^{2}$. The experiment was planned in split-split design with varieties in main plot, inducers in sub-plots and doses in sub-subplots with 3 replications. Each plot consists 6 rows of 15 chickpea plants/row. Garlic (Allium sativum L.), neem (Azadirachta indica Juss.) and datura (Datura metel L.) extracts were prepared from their leaves collected from research areas while cloves of garlic from local market were purchased. Leaves of neem, datura were washed in distilled water, surface sterilized with $2 \%$ solution of sodium hypochlorite for 2-min and rinsed with double distilled water before homogenizing (Yellow line DI-25 Basic-GmbH and $\mathrm{CO}$, Germany) in sterile double distilled water $(1: 1 \mathrm{w} / \mathrm{v})$, and filtering through a muslin cloth. Fresh garlic extracts were prepared by removing the outer, dry peel, surface-sterilizing in ethanol (70\%) for 2 min and washed in distilled water. Cloves crushed in porcelain mortar with pestle; the pulp (soft tissues) was poised in $100 \mathrm{ml}$ water in $250 \mathrm{ml}$ conical flask and filtered by muslin cloth (cotton fabric) (Rasul et al., 2012). Extracts were heated @ $40^{\circ} \mathrm{C}$ for $12 \mathrm{~min}$ to evade any contamination (Kamalakannan, 2001) and diluted to $5 \%, 10 \%$ and $15 \%$ concentration. Aqueous solutions of salicylic acid $(0.5,1.0,1.5 \mathrm{mM})$, Bion ${ }^{\oplus}$ $(0.4,0.8,1.2 \mathrm{mM})$ and $\mathrm{KOH}(25,50,75 \mathrm{mM})$ were applied, at early flowering, the plant extracts and 
chemicals were sprinkled on the plants until run off while the control plants were sprayed only with distilled water. Inoculum was prepared from already preserved culture of $A$. rabiei isolated from disease samples using method of Ilyas and Khan (1986) and the conidia concentrations were adjusted through haemocytometer. Plants were sprayed after 4 days to excess with spore suspension $\left(1 \times 10^{5}\right.$ spores $\left.\mathrm{L}^{-1}\right)$ that contained 3-drops/liter of Tween-80 as surfactant at night to give improved germination of conidia spores. Spray inoculation sustained for 3-days to make sure utmost infection of plants. The plants were periodically sprinkled with water to uphold moisture and support conidial growth.

\section{Reduction percentage}

Disease reduction (\%) was measured 14 days after post-treatment via mixed quantitative and qualitative scale (0 9 rating scale) and transformed to disease reduction percentage by formula having slight modification (Tivoli et al., 2006).

Diseases reduction $(\%)=\frac{\sum(\text { No. of plants in a category value } \times \text { category value })}{\text { Total No. of plants } \times \text { maximum category value }} \times 100$

\section{Analysis of amino acids}

The plant samples were collected from the induced (un-inoculated and inoculated) with spores of $A$. rabiei. The samples were dried out in dry oven at $55^{\circ} \mathrm{C}$ for $120 \mathrm{~h}$ (to attain stable weight) and ground. In order for the examine of amino acid profile, ground sample $(100 \mathrm{mg})$ was placed in Pyrex glass test tubes $(30 \mathrm{ml})$, prepared by heat stretching in the middle in order to look like a damsel fly. Ten $\mathrm{mL}$ of $6 \mathrm{~N} \mathrm{HCl}$ (reagent grade) was added to each of these test tubes. The oxygen from these test tubes was removed by a continuous flow of nitrogen gas. The test tubes were sealed with a pin point oxygen flame. The preserved test tubes were located in standing position in dry oven at $110 \pm 1^{\circ} \mathrm{C}$ for 22 hours. The tubes were permitted at room temperature to cool. The hydrolyzate so formed was evaporated in vacuum @ $60^{\circ} \mathrm{C}$ for drying. The dry film of hydrolyzate dissolved in $5-\mathrm{mL}$ of $0.02 \mathrm{~N} \mathrm{HCl}$ $(\mathrm{pH}=2.2)$. The soluble material was centrifuged to remove the sediments and the samples were stored in glass stoppered bottles at $4^{\circ} \mathrm{C}$ until used for amino acid analysis. $20 \mu \mathrm{L}$ of the hydrolyzate was loaded on ion exchange column of amino acid analyzer (Hitachi L-8500-automatic A, Japan) installed in the Central High-Tech Laboratory, UAF. Acidic, neutral amino acids were eluted with sodium citrate buffer at $\mathrm{pH}$ 3.25 and 4.25 , respectively. The elusion was done at flow rate of 15 and $30 \mathrm{~mL} /$ hour for ninhydrin and citrate buffer, respectively. The concentration of amino acids was calculated by the following formula:

\section{Amino acid (\%) = Peak area/constant}

Methionine, iso-leucine, leucine, tyrosine and phenylalanine were determined by the Amino Acid Analyzer in the form of graphic peaks and the concentration of each amino acid was quantified by the above mentioned formula.

\section{Statistical analysis}

The experiment was planned with 3 replicates and result were evaluated with ANOVA, tested through Duncan's multiple range test to monitor differences among treatment means at 5\% (0.05) significant level (Steel et al., 1997).

\section{Results and Discussion}

\section{Reduction (\%) in disease after application of resistance inducers}

The significant disease reduction (79\%) was observed by $\mathrm{Bion}^{\otimes}$ in cultivar C-44@1.2mM as compared with salicylic acid and the least was seen by $\mathrm{KOH}$ (Table 1). Among different extracts, utmost disease reduction (43.5\%) observed by the application of $A$. indica (leaf extract) while $A$. sativum proved as least effective.

\section{Methionine contents}

All the main effects (inoculation, varieties, and concentrations) were significant and their associated interactions (inoculation $\times$ varieties, inoculation $\times$ concentration, varieties $\times$ concentration, inoculation $x$ varieties $\times$ concentration) were non-significant in case of chemicals while significant in case of plant extracts. As regards, methionine contents of induced plants (un-inoculated and inoculated) of chickpea cultivars were concern; it increased in all the treatments $(P \leq 0.05)$ upon inoculation with $A$. rabiei (Figure 1 ). The more methionine content was more (from 156.3 to $178.76 \mu \mathrm{g} / 100 \mathrm{mg}$ ) in the cultivar C-44 by the application of Bion and this was followed by more content in Pb-91 and Bittle- 98 . Salicylic acid also increases the methionine content more (85.3 to $106.3 \mu \mathrm{g} / 100 \mathrm{mg}$ ) and the least was in case of $\mathrm{KOH}$ application (26.43 to $49.43 \mu \mathrm{g} / 100 \mathrm{mg}$ ) in cultivar Bittle-98 after inoculation and induction. Plant extracts also increased the methionine content 
Table 1: Mean comparison of (\%) percent protection ( \pm S.E) in A. rabiei in cultivars $C-44, P b-91$ and Bittle-98 after 14 days of the treatments with resistance inducers (chemicals and plant extracts).

\begin{tabular}{|c|c|c|c|c|c|c|c|c|c|}
\hline \multirow{3}{*}{ Treatments } & \multicolumn{9}{|c|}{ Cultivars } \\
\hline & \multicolumn{3}{|c|}{ C-44 } & \multicolumn{3}{|c|}{$\mathrm{Pb}-91$} & \multicolumn{3}{|c|}{ Bittle-98 } \\
\hline & \multicolumn{9}{|c|}{ Doses (Mm) } \\
\hline Salicylic acid & 0.5 & 1.0 & 1.5 & 0.5 & 1.0 & 1.5 & 0.5 & 1.0 & 1.5 \\
\hline $14^{\text {th }}$ days & $32.40 \pm 3.0$ & $43.50 \pm 0.92$ & $56.80 \pm 1.45$ & $25.36 \pm 1.47$ & $26.88 \pm 2.39$ & $37.23 \pm 0.99$ & $22.40 \pm 0.40$ & $24.57 \pm 0.70$ & $29.18 \pm 0.55$ \\
\hline Bion & 0.4 & 0.8 & 1.2 & 0.4 & 0.8 & 1.2 & 0.4 & 0.8 & 1.2 \\
\hline $14^{\text {th }}$ days & $44.10 \pm 1.05$ & $62.83 \pm 0.89$ & $79.33 \pm 0.48$ & $34.33 \pm 1.44$ & $44.55 \pm 0.54$ & $51.27 \pm 1.02$ & $34.42 \pm 0.55$ & $36.05 \pm 0.90$ & $44.16 \pm 0.60$ \\
\hline $\mathrm{KOH}$ & 25 & 50 & 75 & 25 & 50 & 75 & 25 & 50 & 75 \\
\hline $14^{\text {th }}$ days & $15.33 \pm 2.84$ & $21.09 \pm 2.40$ & $22.88 \pm 1.29$ & $13.53 \pm 3.94$ & $17.96 \pm 3.94$ & $17.96 \pm 3.94$ & $12.44 \pm 1.23$ & $16.09 \pm 3.94$ & $16.65 \pm 1.32$ \\
\hline A. indica & $5 \%$ & $10 \%$ & $15 \%$ & $5 \%$ & $10 \%$ & $15 \%$ & $5 \%$ & $10 \%$ & $15 \%$ \\
\hline $14^{\text {th }}$ days & $14.69 \pm 3.41$ & $29.41 \pm 3.91$ & $43.52 \pm 4.11$ & $12.05 \pm 2.44$ & $16.13 \pm 2.75$ & $20.52 \pm 3.98$ & $12.03 \pm 3.17$ & $15.49 \pm 3.64$ & $17.77 \pm 3.02$ \\
\hline D. metel & $5 \%$ & $10 \%$ & $15 \%$ & $5 \%$ & $10 \%$ & $15 \%$ & $5 \%$ & $10 \%$ & $15 \%$ \\
\hline $14^{\text {th }}$ days & $14.28 \pm 2.60$ & $16.25 \pm 2.57$ & $31.41 \pm 3.08$ & $10.17 \pm 2.23$ & $12.77 \pm 2.47$ & $19.52 \pm 2.66$ & $9.67 \pm 2.33$ & $11.08 \pm 2.15$ & $17.07 \pm 3.07$ \\
\hline A. sativum & $5 \%$ & $10 \%$ & $15 \%$ & $5 \%$ & $10 \%$ & $15 \%$ & $5 \%$ & $10 \%$ & $15 \%$ \\
\hline $14^{\text {th }}$ days & $12 \pm 2.64$ & $14.09 \pm 1.56$ & $26.72 \pm 3.81$ & $10.19 \pm 2.75$ & $12.43 \pm 3.56$ & $16.06 \pm 3.32$ & $9.66 \pm 3.18$ & $11.07 \pm 3.28$ & $13.81 \pm 2.43$ \\
\hline
\end{tabular}

but less quantity as compared with chemicals. The maximum (64.3 to $88.3 \mu \mathrm{g} / 100 \mathrm{mg}$ ) was produced in case of neem leaf extract, followed by $\mathrm{Pb}-91$ and Bittle-98. Methionine content was very (low 7.5 to $22.6 \mu \mathrm{g} / 100 \mathrm{mg}$ ) after treatment with garlic extract in the cultivar Bittle-98.

\section{Iso-leucine contents}

Isoleucine contents of induced (un-inoculated and inoculated) plants is presented in Figure 2 which exhibited that all the main effects were significant and their associated interactions were non-significant in case of chemicals while significant in case of plant extracts. In general, there was a tendency of significant increased $(P \leq 0.05)$ in isoleucine content in all the three cultivars of chickpea as a result of inoculation with the pathogen. Thus, there is an increase (from 176.33 to $197.36 \mu \mathrm{g} / 100 \mathrm{mg}$ ) in $\mathrm{C}-44$ followed by $\mathrm{Pb}-91$ and Bittle-98 after treatment with Bion. The application of salicylic acid increases the isoleucine content with maximum in $(132.53 \mu \mathrm{g} / 100 \mathrm{mg})$ in cultivar C-44 followed by $\mathrm{Pb}-91$ (105.2 $\mu \mathrm{g} / 100$ $\mathrm{mg})$ and Bittle-98 (81.93 $\mu \mathrm{g} / 100 \mathrm{mg})$. Application of $\mathrm{KOH}$ also enhanced the isoleucine content but was not too high as compared to Bion and salicylic treatment and inoculated pathogen. Garlic extract with highest ( 24.23 to $40.3 \mu \mathrm{g} / 100 \mathrm{mg}$ ) isoleucine content in C-44 was quite low as in case of neem and datura extract. The lowest content was recorded in Bittle-98 with (50.4, 44.66 and $27.23 \mu \mathrm{g} / 100 \mathrm{mg}$ ) after application of neem, datura and garlic extracts.
Over all the trend of increased isoleucine content was observed in chemicals treatment as compared to plant extracts.

\section{Leucine contents}

The leucine contents of the chickpea cultivar belonging to the two groups are given in (Figure 3) which exhibited that all the main effects were significant $(P \leq 0.05)$ and their associated interactions were non-significant in case of chemicals while significant in case of plant extracts. The cultivar C-44 after application of garlic extract, the increase ranges from (86.83 to $106.0 \mu \mathrm{g} / 100 \mathrm{mg}$ ) followed by (76.36 $\left.\mu \mathrm{g} / 100 \mathrm{mg}^{-1}\right)$ in $\mathrm{Pb}-91$ and $(53.3 \mu \mathrm{g} / 100 \mathrm{mg})$ in Bittle-98. Neem extract with $(161.4 \mu \mathrm{g} / 100 \mathrm{mg})$ was considered as best among all the extract in increasing the leucine content. The extract of datura was also proved effectual but less to neem.

The application of chemical and then inoculation with plant pathogen increases the leucine content but it was more significant in Bion treated plants in all the varieties $(501.4,473.16$ and $463.36 \mu \mathrm{g} / 100 \mathrm{mg}$ ) in $\mathrm{C}-44, \mathrm{~Pb}-91$ and Bittle-98. This tendency was also followed by the application of salicylic acid with $(305.23 \mu \mathrm{g} / 100 \mathrm{mg})$ content of leucine in cultivar C-44 followed (284.26, $241.43 \mu \mathrm{g} / 100 \mathrm{mg})$ by $\mathrm{Pb}-$ 91 and Bittle-98. Leucine content of $(246.2 \mu \mathrm{g} / 100$ $\mathrm{mg}$ ) was produced by the application of $\mathrm{KOH}$ in the cultivar C-44 while (204.26 and $168.2 \mu \mathrm{g} / 100 \mathrm{mg}$ ) was produced in cultivar $\mathrm{Pb}-91$ and Bittle-98. 

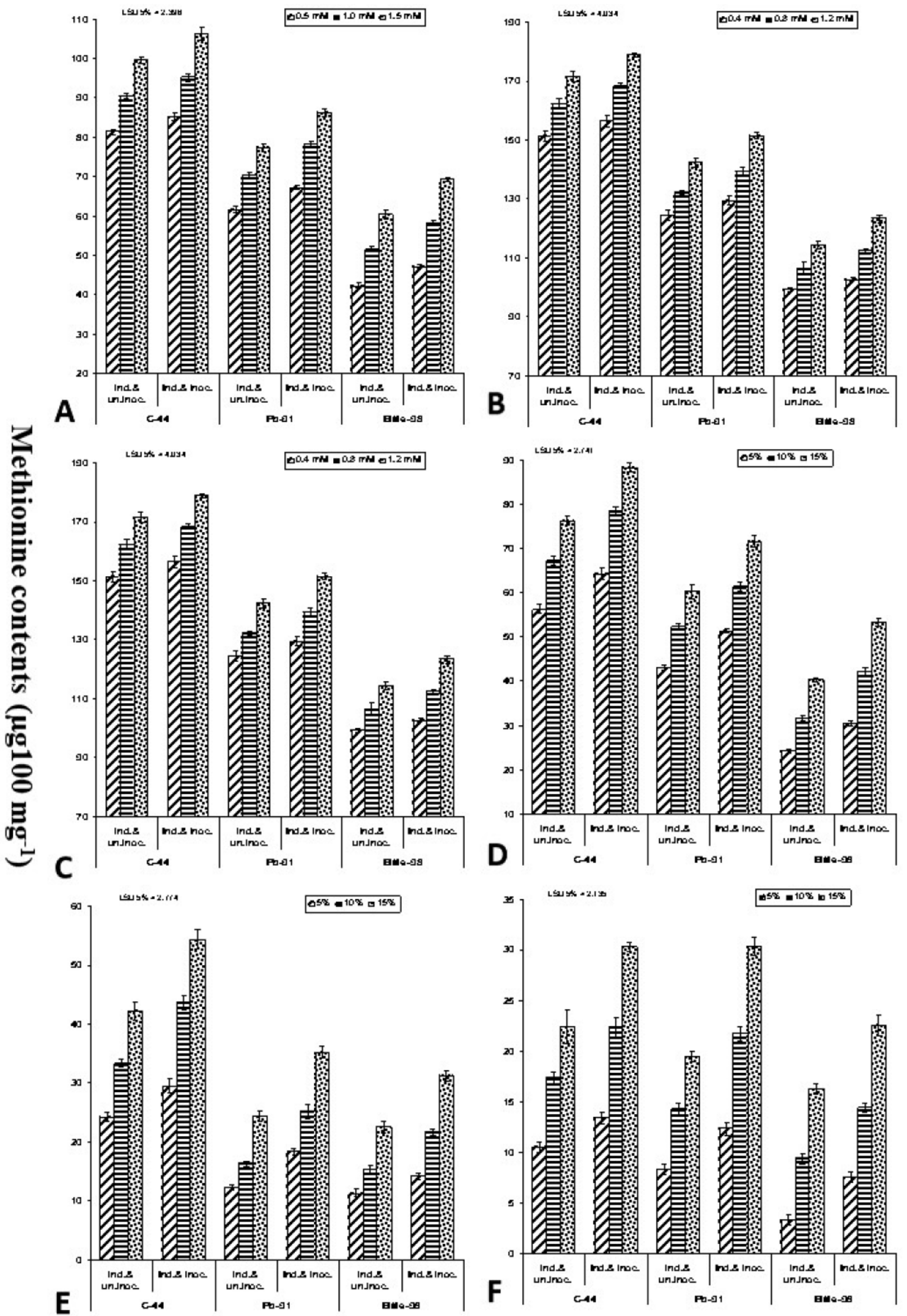

Figure 1: Mean comparison of Methionine contents $\left(\mu \mathrm{g} .100 \mathrm{mg}^{-1}\right)$ after $14^{\text {th }}$ days of induction of resistance by the application of $(A)$ salicylic acid, (B) Bion, (C) KOH, (D) Neem, (E) Dautra, (F) Garlic and by un-inoculation and inoculation with Ascochyta rabiei in cultivars C-44, Pb-91, Bittle-98. Data are means of three repeated experiments. The error bar represents the standard error of the mean according to the least significant difference test at $P \leq 0.05$. 




Figure 2: Mean comparison of Isolucine contents $\left(\mu \mathrm{g} .100 \mathrm{mg}^{-1}\right)$ after $14^{\text {th }}$ days of induction of resistance by the application of $(A)$ salicylic acid, (B) Bion, (C) KOH, (D) Neem, (E) Dautra, (F) Garlic and by un-inoculation and inoculation with Ascochyta rabiei in cultivars C-44, Pb-91, Bittle-98. Data are means of three repeated experiments. The error bar represents the standard error of the mean according to the least significant difference test at $P \leq 0.05$. 



Figure 3: Mean comparison of Leucine contents $\left(\mu \mathrm{g} .100 \mathrm{mg}^{-1}\right)$ after $14^{\text {th }}$ days of induction of resistance by the application of $(A)$ salicylic acid, (B) Bion, (C) KOH, (D) Neem, (E) Dautra, (F) Garlic and by un-inoculation and inoculation with Ascochyta rabiei in cultivars C-44, Pb-91, Bittle-98. Data are means of three repeated experiments. The error bar represents the standard error of the mean according to the least significant difference test at $P \leq 0.05$. 



ment
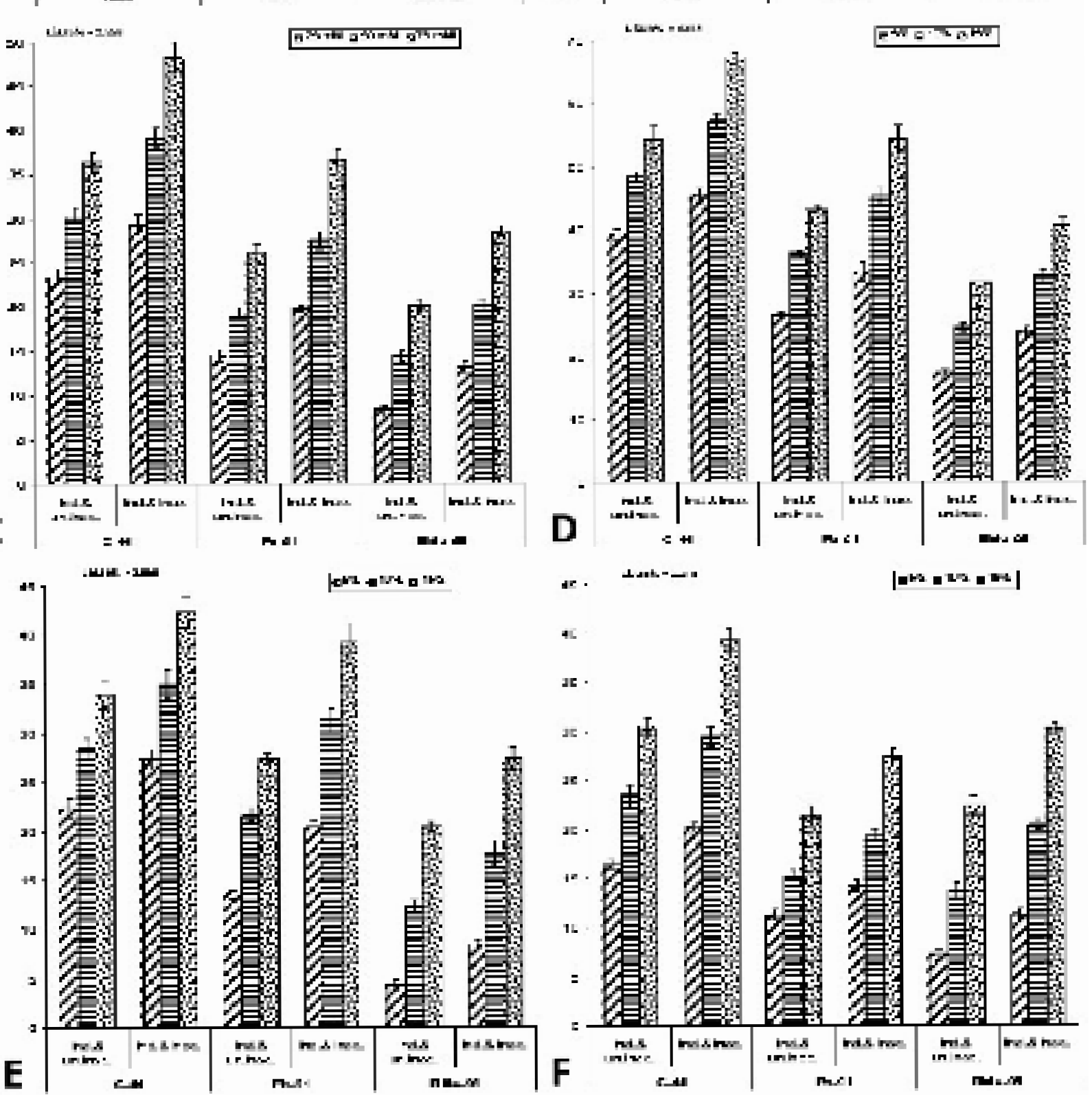

Figure 4: Mean comparison of Tyrosine contents $\left(\mu \mathrm{g} 100 \mathrm{mg}^{-1}\right)$ after $14^{\text {th }}$ days of induction of resistance by the application of $(A)$ salicylic acid, (B) Bion, (C) KOH, (D) Neem, (E) Dautra, (F) Garlic and by un-inoculation and inoculation with Ascochyta rabiei in cultivars C-44, Pb-91, Bittle-98. Data are means of three repeated experiments. The error bar represents the standard error of the mean according to the least significant difference test at $P \leq 0.05$. 

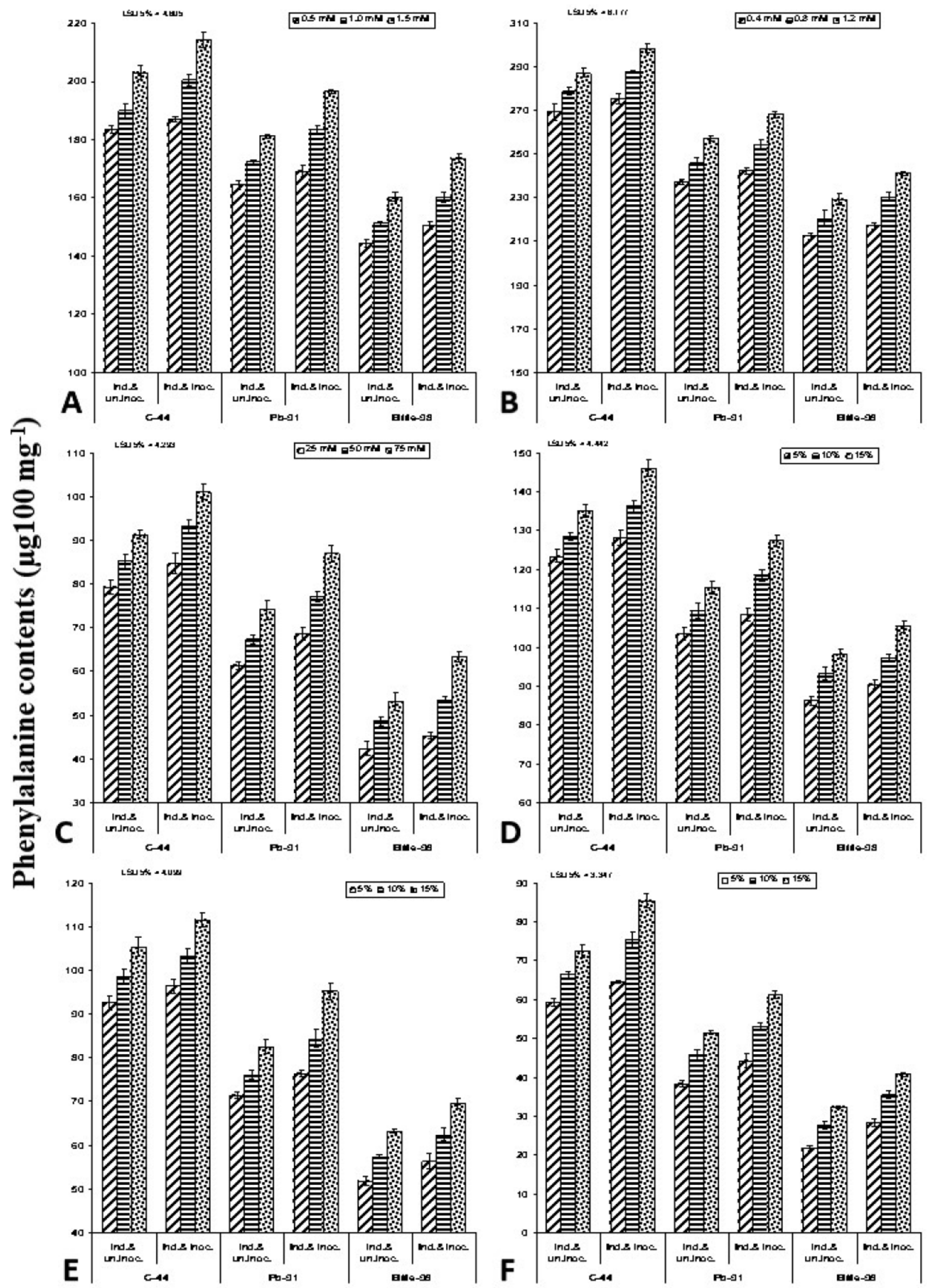

Figure 5: Mean comparison of Phenylalanine contents $\left(\mu \mathrm{g} .100 \mathrm{mg}^{-1}\right)$ after $14^{\text {th }}$ days of induction of resistance by the application of $(A)$ salicylic acid, (B) Bion, (C) KOH, (D) Neem, (E) Dautra, (F) Garlic and by un-inoculation and inoculation with Ascochyta rabiei in cultivars $C-44$, Pb-91, Bittle-98. Data are means of three repeated experiments. The error bar represents the standard error of the mean according to the least significant difference test at $P \leq 0.05$. 
Tyrosine contents

All the main effects were significant $(P \leq 0.05)$ and their associated interactions were non-significant in case of chemicals while significant in case of plant extracts. The quantity of tyrosine in the induced uninoculated and inoculated plants of three chickpea cultivar demonstrated increase trend in case of application of resistance inducers and plant extracts (Figure 4). Salicylic acid application in all the cultivars under study, gave increase (41.4 to $64.16 \mu \mathrm{g} / 100 \mathrm{mg}$ ) tyrosine content as compared to un-inoculated plants (36.33 to $54.23 \mu \mathrm{g} / 100 \mathrm{mg}$ ). Tyrosine content was also on higher side in $\mathrm{Pb}-91(51.23 \mu \mathrm{g} / 100 \mathrm{mg})$ and Bittle-98 (45.2 $\mu \mathrm{g} / 100 \mathrm{mg})$. The maximum increase (61.7 to $83.23 \mu \mathrm{g} / 100 \mathrm{mg}$ ) was recorded in case of Bion application in cultivar $\mathrm{C}-44$ which was different in case of $\mathrm{Pb}-91(67.6 \mu \mathrm{g} / 100 \mathrm{mg})$ and Bittle-98 $(50.33 \mu \mathrm{g} / 100 \mathrm{mg})$. The application of $\mathrm{KOH}$ in all the three cultivars increased (48.26, 36.53 and 28.53 $\mu \mathrm{g} / 100 \mathrm{mg}$ ) the tyrosine content but the increase was less as compared to Bion application. Among the plant extract only the neem leaf extract produced (67.26 $\mu \mathrm{g} / 100 \mathrm{mg}$ ) tyrosine content in C-44 as compared to $(54.32$ and $40.5 \mu \mathrm{g} / 100 \mathrm{mg}$ ) in the cultivar $\mathrm{Pb}$ 91 and Bittle-98. Garlic and dutara extract resulted in increasing the content of tyrosine with maximum $(42.3 \mu \mathrm{g} / 100 \mathrm{mg})$ in case of C-44. It is interesting to note that Bittle-98 exhibited slight increase $(30.3 \mu \mathrm{g} / 100 \mathrm{mg})$ tyrosine content in induced and inoculated as compared to $\mathrm{Pb}-91(27.36 \mu \mathrm{g} / 100 \mathrm{mg})$.

\section{Phenylalanine contents}

All the main effects (inoculation, varieties, concentrations) were significant and their associated interactions (inoculation $\mathrm{x}$ varieties, inoculation $\mathrm{x}$ concentration, varieties $x$ concentration, inoculation $x$ varieties $\mathrm{x}$ concentration) were non-significant in case of chemicals while significant in case of plant extracts. The phenylalanine contents of all the three cultivars showed increase trend $(298.3,268.2$ and $241.2 \mu \mathrm{g} / 100$ $\mathrm{mg}$ ) in $\mathrm{C}-44, \mathrm{~Pb}-91$ and Bittle-98 (Figure 5). $\mathrm{KOH}$ application in inoculated plants showed enhance $(P \leq$ $0.05)$ tendency but it was less $(63.43 \mu \mathrm{g} / 100 \mathrm{mg})$ as compared to Bion and salicylic acid application There was $(298.3,268$ and $241.2 \mu \mathrm{g} / 100 \mathrm{mg}$ ) phenylalanine content through application of salicylic acid in three cultivars. The plant extracts also effectual in boosting the phenylalanine content $(146.03,127.4$ and 105.33 $\mu \mathrm{g} / 100 \mathrm{mg}$ ) by the application of neem extract in the cultivars C-44, Pb-91 and Bittle-98. Garlic extract increase the phenylalanine contents $(40.76 \mu \mathrm{g} / 100$ $\mathrm{mg}$ ) but it was less as compared to neem and datura extracts. Over all the phenylalanine contents increased in all the cultivars after inoculation of the induced plant although the increase was also observed in uninoculated plants but on comparison basis, it was less after as compared to inoculated plants.

A novel technology in management of diseases of plants is the foundation of the plant defense system with assist of inducers (biotic and abiotic) (Satya et al., 2007). Several chemicals like, salicylic acids and its derivatives (Schreiber and Desveaux, 2008), Bion and Di-potassium Phosphate (Kamal et al., 2008) and plant extracts can induce resistance which is frequently linked with increased action of $\mathrm{PO}$, lignin deposition, increase in phenolic contents, induction of PR-proteins (Hammerschmidt and Kuc, 1982). There are 17 families of pathogenesis related proteins in host pathogen interaction produced in various plants (Tuzan and Somanchi, 2006). These are produced in response of diverse stress related plant hormones counting osmotic stress, ethylene and wounding etc. Pathogenesis related proteins (PR) chitinases and $\beta-1,3$-glucanases break down the $\beta-1,3$-glucans and chitin in the cell wall of fungi but the protection provided by them may vary (Manandhar et al., 1999) and it might depends on genetic makeup, physiological condition of the plant and nature of inducing agent used (Ton et al., 1999). PAL in higher plants considered as the key enzyme of phenyl-propanoid metabolism which catalyzed exchange of phenylalanine into trans-cinnamic acid. It supplied the pre-cursors for flavonoid pigments, lignins and phytoalexins according to data published by Hahlbrock and Scheel (1989). Some studies indicated that disease resistance is associated with the launch of PAL and subsequent increase in phenolic contents in host plants.

The amino acids are necessary and play a variety of main functions such as an osmoprotector, antioxidant defense system (Gill and Tuteja, 2010) and transport and storage of all the nutrients uptake (Teixeira et al., 2019). Amino acids are responsible for the synthesis and build-up of metabolites that collectively form a defence mechanism for an individual. Although first proof of the involvement of amino acid/proteins in resistance was observed by Kuc et al. (1957) in susceptible apple leave and found that petiole injection of phenylalanine made the leaves resistant to Venturia inaequalis, the cause of apple scab disease, yet 
different hypothesis still exist about the association of amino acid in resistance/susceptibility in host pathogen interaction. van Andel (1967) discussed the amino acids role in two way (i) amino acids have direct effect on the pathogen, it kill the pathogen directly possessing fungicidal ability or decrease the pathogenicity. (ii) affect the metabolism of the host due to formation of any compound that is toxic to pathogen. Amino acids like glycine, DL-asparagine, and DL-glutamine found inactive in all tests when they were applied (van Andel, 1958; Samborski and Forsyth, 1960; Papavizas and Davey,1963), while DLIysine, DL-proline, hydroxyproline, caused serious injury to the plants (van Andel, 1958; Samborski and Forsyth, 1960).

Methionine in plants acts as precursor of number of crucial biomolecules such as polyamine, vitamins, antioxidants such as glutathione which played an important role in many defense compounds. Moreover, it metabolic sulfide contributor for making of glutathione through fixing inorganic sulfur from the environment leads the formation of secondary metabolites toxic to biotic agents (Khan et al., 2019; Shekari et al., 2017; Yakhin et al., 2017). Leucine, isoleucine along with valine and histidine are termed essential in the growth of plants and energy-rich compounds such as acetyl-CoA and propionylCoA (Gipson et al., 2017; Lea and Azevedo, 2017). Tyrosine considered as an aromatic amino acid which is vital key of several secondary metabolites like cyanogenic glycosides alkaloids, phenylquinones that performs physiological roles as attractants, antioxidants, defense compounds and electron carriers (Munir et al., 2019). It is also considered as basic candidate among disease-resistance genes by downstream specialized metabolites that help plants to survive under different un favorable environmental conditions. Phenylalanine is important amino acid intensify the formation of secondary metabolites (Feduraev et al.,2020) such as phenols and lignin that is integral part of plant defense against biotic stress.

The chickpea cultivar exhibited amplifies in lysine contents more in C-44 ahead inoculation in case of Bion and SA (salicylic acid) treatment but it decreases in Bittle-98. Methionine, isolucine, tyrosine and phenylalanine contents were also increased after induction and inoculation. During the earlier studies (Bhatti et al., 1987) reported only two amino acids namely, methionine and cystine but the authors were unable to quantify the amount of two amino acids recovered from the resistant cultivar (CM-72) and the susceptible cultivar (6153) of chickpea. Only one study regarding the induction of resistance in chickpea against A.rabiei reported an increase in phenolic and peroxidase contents after treatment with salicylic acid (Chaudhry et al, 2001). Hence, the present results could not be compared to the aforementioned studies. These results were partially in line with the findings of Sahi (1999) but contrary to those of Randhawa (1994) who observed marked decrease in the content of total amino acids in both the chickpea groups, resistant as well as susceptible to Ascocbyta rabiei. Similarly, Gokulakumar and Narayanaswamy, 2009 found that Serine, Arginnine, phenylalanine and leucine are higher in resistant roots and lower in disease plant roots in fifteen sesame cultivars after the attack of Macrophomina phaseolina. Present study clearly indicates that upon inoculation in the three susceptible cultivars of chickpea, the appreciable increase was recorded by the application of chemicals than by the extracts, it might be due to more production of PRs proteins. Among the plant extracts, neem leaf extract enhances the amino acid content more as compared to datura and garlic extract. These results are in line with that of Singh and Prithiviraj (1997) reported that Neemazal is the main factor which induce resistance in pea plant beside Erysiphe pisi and directly associated in increasing PAL activity. Paul and Sharma (2002) observed that extract of neem (leaves) provided superior control against Drechslera graminea on barley and exhibited considerably high activity of PAL.

The results of the present studies are also similar to Lewis and MC Clure (1975) who reported that upon infection, in the root-knot susceptible cultivars (M8) there is greater increase in certain individual amino acids than the resistant cultivar (Clevewilt) but in general the sum total of free amino acids were highest in the resistant cultivar further free amino acid content of tissues has been connected to the susceptibility or resistance of plants to other plant pathogens, as in our case there in increase in the amino acid content after inoculation with $A$. rabiei likewise as in case of $\mathrm{C}-44$ the highest amount of alanine was recorded similar to results of (Lakshminarayanan, 1955) who reported that cystine and alanine played significant role in resistance to different plant diseases caused by Fusarium sp. (Hashem and Rehim, 1967). A relationship also exists among the level of alanine 
and susceptibility to Verticillium by cotton (Booth, 1969; Singh et al., 1971). Similarly, more recently Matsubara et al. (2010) reported the influence of arbuscular mycorrhizal fungi (AMF) on total amino acid contents production in plants of strawberry, after inoculation with Glomus mosseae yielded more amino acids among them Serine, glutamic acid, leucine and GABA were higher in both mycorrhizal plants after inoculation as compared to un-inoculated plants with/ out the influence of phosphorus. Amino acids and carbohydrates in nine clone of cacao were analyzed revealed that several amino acids were acknowledged but total amino acid content was $74.5 \%$ higher in the less susceptible as compared to highly susceptible clone and the prevalence of each in the pods diverse with the genotype and with the treatment (Omokolo et al., 2002). Aspartic acid, tyrosine and valine showed a gradual increase with advancing age in case of infection with Fusarium solani to turmeric plants (Reddy et al., 2005).

\section{Conclusions and Recommendations}

In conclusion, Bion provided maximum protection against $A$. rabiei at highest dose rate 14 days post application. Its application correspondingly mitigated the disease by activated the five essential amino acid synthesis so, our findings also suggest that Bion can be augmented in successful management of chickpea blight under the field conditions.

\section{Novelty Statement}

The aim of present study was to elucidate the changes in amino acids after induction of resistance with chemicals and plant extracts under $A$. rabiei stressed field conditions which were never explored comprehensively.

\section{Author's Contribution}

MUG conceived and designed research and wrote the manuscript. WW analyzed the data and help in conduct of experiments. STS supervised the experiment and improved the draft. WR helped in analysis and submission of paper. MAR analyzed the data and reviewed the manuscript.

\section{Conflict of interest}

The authors have declared no conflict of interest.

\section{References}

Ahmad, H.U., K.F. Chang, S.F. Hwang, B.D. Gossen, R.J. Haward and T.D. Warkintin. 2006. Components of disease resistance in Desi and Kabuli chickpea varieties against Ascochyta blight. Plant Pathol. J., 5: 336-342.

Ajay, D. and U.I. Baby. 2009. Induction of systemic resistance to Exobasidium vexans in tea through SAR elicitors. Phytopara.

Altamiranda, E.A.G.,A.B.Andreu, G.R.Daleo and F.P. Olivieri.2008. Effect of $\beta$ aminobutyric acid (BABA) on the protection against Phytophthora infestans throughout the potato crop cycle. Aust. Plant Pathol., 37: 421-427.

Bashir, M. and B.A. Malik. 1988. Diseases of major pulse crops in Pakistan. A review, Trop. Pest Manage., 34(3): 309-314.

Bhatti, A.H., M. Ali and A. Hussain. 1987. Fifteen years of NIAB. Third five years report. Nucl. Inst. Agric. Biol., Faisalabad. pp.84-92.

Boava, L.P., O.J. Kuhn, S.F. Pascholati, R.M. Di Piero and E.L. Furtado. 2009. Effect of acibenzolar-S-methyl and Saccharomyces cerevisiae on the activation of Eucalyptus defenses against rust. Aust. Plant Pathol., 38: 594-602.

Booth, J.A., 1969. Gossypium birsutum tolerance to Verticillium albo-atrum infection, I, Amino acid exudation from aseptic roots of tolerant and susceptible cotton. Phytopathology, 59: 43-46.

Chaube, H.S. and B.K. Pandey. 1986. Transmission of seed borne inoculum of Ascochyta rabiei (Pass.) Labr. in chickpea seedlings. Bull. P1. Appl. Sci., 5: 18.

Chaudhry, Z.H.M., N. Sarwar and F.A. Chaughtai. 2001. Biochemical changes in chickpea plant after induction treatment with simple chemicals for systemic resistance against ascochyta blight in the field. J. Chem. Soc. Pak., 23: 182-186.

Cheng, Q. W. Jia, C. Hu, G. Shi, D. Yang, M. Cai and X. Zhao. 2020. Enhancement and improvement of selenium in soil to the resistance of rape stem against Sclerotinia sclerotiorum and the inhibition of dissolved organic matter derived from rape straw on mycelium. Environ. Pollut., pp. 114827. https://doi.org/10.1016/j. envpol.2020.114827

Davidson, J.A. and R.B. Kimber. 2007. Integrated disease management of ascochyta blight in pulse crops. In Ascochyta blights of grain legumes. 
Springer, Dordrecht. pp. 99-110. https://doi. org/10.1007/978-1-4020-6065-6_10

Ejeta, A., T. Selvaraj and A. Lencho. 2017. Evaluation of fungicides sprays intervals for the management of chickpea Ascochyta blight (Ascochyta rabiei (Pass.) Lab.) in Alemtena, East Showa. Ethiop. J. Agric. Sci., 1: 1-24.

Feduraev, P., L, Skrypnik, A. Riabova, A. Pungin, E. Tokupova, P. Maslennikov and G. Chupakhina. 2020. Phenylalanine and Tyrosine as Exogenous Precursors of Wheat (Triticum aestivum L.) Secondary Metabolism through PAL-Associated Pathways. Plants, 9: 476.

Ghazanfar, M.U., S.T. Sahi, N. Javed and W. Wakil. 2010a. Response of advanced lines of chickpea against chickpea blight disease. Pak. J. Bot., 42: 3423-3430.

Ghazanfar, M.U., S.T. Sahi and W. Wakil. 2010b. Effect of Ascochyta blight on the agronomic characters of selected chickpea cultivars/lines. Pak. J. Phytopathol., 22: 113-119.

Gill, S. and N. Tuteja. 2010. Reactive oxygen species and antioxidant machinery in abiotic stress tolerance in crop plants. Plant Physiol. Biochem., 48: 909-930.

Gillmeister, M., S. Ballert, A. Raschke, J. Geistlinger, K. Kabrodt, H. Baltruschat, $\mathrm{H}$ and I. Schellenberg. 2019. Polyphenols from rheum roots inhibit growth of fungal and oomycete phytopathogens and induce plant disease resistance. Plant Dis. 103(7): 1674-1684. https://doi.org/10.1094/PDIS-07-18-1168$\mathrm{RE}$

Gipson, A.B., K.J. Morton, R.J. Rhee, S. Simo, J.A. Clayton, M.E. Perrett and K.A. Rouhier. 2017. Disruptions in valine degradation affect seed development and germination in Arabidopsis. Plant J., 90(6): 1029-1039.

Gokulakumar, B. and R. Narayanaswamy. 2009. High performance liquid chromatography for the estimation and detection of amino acids in root rot disease in sesame. Adv. Biol. Res., 3: 162-167.

Gozzo, F., 2003. Systemic resistance in crop protection: from nature to a chemical approach. J. Agric. Food Chem., 51: 4487-4503.

Hahlbrock, K. and D. Scheel. 1989. Physiology and molecular biology of phenylpropanoid metabolism. Ann. Rev. Plant Physiol. Plant Mol. Biol., 40: 347-369.

Hammerschmidt, R. and J. Kuc. 1982. Lignification as a mechanism for induced systemic resistance in cucumber. Physiol. Plant Pathol., 20: 61-71.

Hashem, M. and M.A.A. Rehim. 1967. The possible role of amino acids in resistance of plants to fungal infection. Flora. 158: 265-269.

Hutcheson, S., 1998. Current concepts of active defense in plants. Ann. Rev. Phytopathol., 36: 59-90.

Ilyas, M.B and I.U. Khan. 1986. A low cost easy technique for the culturing of Ascochyta rabiei fungus. Pak. J. Agric. Sci., 23: 60.

Ilyas, M.B., 1999. Production constraints of pulses in Pakistan. Proc. $2^{\text {nd }}$ National Conf. Pant Pathol., Sept.27-29, 1999. Univ. of Agri., Faisalabad. pp.36-40.

Iqbal, S.M., A. Ghafoor, A. Bakhsh and M. Bashir. 2002. Disease resistance status of chickpea genotypes against Ascochyta blight. Pak. J. Phytopathol., 14: 135-139.

Jamil, F.F., N. Bashir and I. Haq. 1990. Biochemical basis of resistance in chickpea against Ascochyta blight. In: Proc. Nat. Chem. Conf., pp. 114-117.

Kadiri, A., Z.F. Boukhatem, Y. Halfaoui and Z. Ighilhariz. 2019. Chickpea Callus Histology Inoculated with Ascochyta Rabiei and nbsp; Blight Causal Agent Spores. Int. J. Agric. Innov. Res., 3(1): 112-122.

Kaiser, W.J., 1984. Control of ascochyta blight of chickpea through clean seed. In: Ascochyta blight and winter sowing of chickpea. Ed. Martinus Nijkoff, Dr. W. Junk Publishers, Hague, The Natherlands.

Kamal, Abo-E.A.M., M.M.A. Mohamed, A.A.D. Aly and H.A.H. Mohamed. 2008. Enhanced onion resistance against stemphylium leaf blight disease, caused by Stemphylium vesicarium, by Di-potassium phosphate and benzothiadiazole Treatments. Plant Pathol. J., 24: 171-177.

Kamalakannan, A., V. Shanmugam and M. Surendran. 2001. Effect of plant extracts on susceptibility of rice seedlings to blast disease and consequent biochemical changes in rice plants. J. Plant. Dis. Protec., 536-543.

Kessmann, H., T. Staub, C. Hofmann, T. Maetzke, J. Herzog, E. Ward, S. Uknes and Ryals. 1994. Induction of systemic acquired disease resistance in plants by chemicals. Annu. Rev. Phytopathol., 32: 439-459. https://doi.org/10.1146/annurev. py.32.090194.002255

Khan, S., H. Yu, Q. Li, Y. Gao, B.N. Sallam, H. Wang and W. Jiang. 2019. Exogenous 
application of amino acids improves the growth and yield of lettuce by enhancing photosynthetic assimilation and nutrient availability. Agro, 9(5): 266.

Komives, T. and Z. Kiraly. 2019. Disease resistance in plants: The road to phytoalexins and beyond. Ecocycles, 5(1): 7-12.

Kuc, J., 2001. Concepts and direction of induced systemic resistance in plants and its application. Eur. J. Plant Pathol., 107: 7-12.

Kuc, J., E.B. Williams and J.R. Shay. 1957. Increase of resistance to apple scab following injection of host with phenylthiourea and D-phenylalanine. Phytopathology, 47: 21-22.

Lakshminarayanan, K., 1955. Role of cystine chelation in the mechanism of Fusarium wilt of cotton. Experimentia, 9: 388.

Lea, P.J. and R.A. Azevedo. 2017. Amino acids, encyclopedia of applied plant sciences, $2^{\text {nd }}$ edition, Volume 2. https://doi.org/10.1016/ B978-0-12-394807-6.00160-X

Lewis, S.A. and M.A. Mc-clure. 1975. Free amino acids in roots of infected cotton seedlings resistant and susceptible to Meloidogyne incognita. J. Nematol., 7: 10-15.

Lyon, G.D. and A.C. Newton. 1999. Induced plant defenses against pathogens and herbivores, APS Press, St Paul, Minnesota, pp. 299-318.

Malik, B.A. and M. Bashir. 1984. Strategies for controlling gram blight. Prog. Farming, 4: 2123.

Malik, B.A. and M. Tufail. 1984. Chickpea production in Pakistan. In: Ascochyta blight and winter sowing of chickpea. Ed. Martinus Nijkoff, Dr. W. Junk Publishers, Hague, The Natherlands. pp. 229-235.

Malik, S.R., S.M. Iqbal and A.M. Haqqani. 2006. Resistance screening to Ascochyta blight disease of chik pea in Pakistan. Int. Chickpea Pigeonpea Newsl., 13: 30-31.

Manandhar, H.K., S.B. Mathur, V. SmedegaardPetersen and H. Thordal-Christensen. 1999. Accumulation of transcripts for pathogenesis related proteins and peroxidase in rice plant triggered by Pyricularia oryzae, Bipolaris sorokinan and UV. light. Physiol. Mol. Plant Pathol., 55: 289-295.

Matsubara,Y.I.,T.Ishigaki and K. Koshikawa.2010. Changes in free amino acid concentrations in mycorrhizal strawberry plants. Sci. Hortic. 119: 392-396.
Mauch, F., B.M. Mani and T. Boller. 1988. Antifungal hydrolases in pea tissue II. Inhibition of fungal growth by combinations of chitinase and $\beta-1,3$-glucanases. Plant Physiol., 88: 936942.

Moore, K., K. Hobson, P. Sambasivam, R. Ford, S. Harmen, P. Nash, G. Chiplin and S. Bithel. 2015. Chickpea ascochyta - is the pathogen changing and what are the implications for management. Available at: https://grdc. com.au/resources-and-publications/grdcupdate-papers/tab-content/grdc-updatepapers/2015/02/chickpea-ascochyta-isthe-pathogen-changing-and-what-are-theimplications-for-management

Motagi, B.N., M.L. Rao and A. Mathad. 2020. Integrated and sustainable management of fungal diseases of chickpea: Current status and challenges. In: Management of Fungal Pathogens in Pulses Springer, Cham. pp. 7391. https://doi.org/10.1007/978-3-030-359478_5

Munir, N., C. Cheng, C. Xia, X. Xu, M.A. Nawaz, J. Iftikhar and Z. Lai. 2019. RNA-Seq analysis reveals an essential role of tyrosine metabolism pathway in response to root-rot infection in Gerbera hybrida. PLoS One, 14(10): e0223519. https://doi.org/10.1371/journal.pone.0223519.

Omokolo, N.D., D.J. Nankeu, N. Niemenak and P.F. Djocgoue. 2002. Analysis of amino acids and carbohydrates in the cortex of nine clones of Theobroma cacao L. in relation to their susceptibility to Phytophthora megakarya Bra. and Grif. Crop Prot., 21: 395-402.

Papavizas, G.C. and C.B. Davey. 1963. Effect of amino compounds and related substances lacking sulfur on Aphanomyces root rot of peas. Phytopathology, 53: 116-122.

Paul, K.P. and P.D. Sherma. 2002. Azadirachta indica leaf extract induce resistance in barley against leaf stripe disease. Physiol. Mol. Plant Pathol., 61: 3-13.

Randhawa, M.A., 1994. Role of some morphological and chemical characters of gram in resistance to Ascochyta blight. Ph.D. thesis Dep. Plant Path., Univ. Agric. Faisalabad, Pakistan. pp. 191.

Rasul, S.H.A., M.S. Butt, F.M. Anjum, F. Saeed, R. Batool and A.N. Ahmad. 2012. Aqueous garlic extract and its phytochemical profile; special reference to antioxidant status. Int. J. Food Sci. 
Nutr., 63(4): 431-439.

Rauf, C.A., M.R. Malik, S.M. Iqbal, S. Rahat and M.Hussain. 1996. Fungicides-an economic tool to enhance productivity and return in chickpea. Sarhad J. Agric., 12: 445-448.

Reddy, M.N., N.V. Sridevi and M.C. Devi. 2005. Changes in the nitrogen fractions and amino acid metabolism of turmeric (Curcuma longa L.) roots infected with Fusarium solani. Plant Pathol. Bull., 14: 221-226.

Reddy, M.V. and K.B. Singh. 1984. Evaluation of world collection of chickpea germplasm accessions for resistance to Ascochyta blight. Plant Dis., 68: 900-901.

Roulin, S. and A.J. Buchala. 1995. Induction of $\beta$-1,3-glucanases and other enzymes in groundnut infected with Cercospora arachidicola. Physiol. Mol. Plant Pathol., 46: 471-489.

Ryals, J.A., U.H. Neuenschwander, M.G. Willits, A. Molina, H.Y. Steiner and M.D. Hunt. 1996. Systemic acquired resistance. Plant Cell, 8: 1809-1819.

Sahi, S.T., 1999. Determination of some morphological and biochemical characters of lentil (Lens culinaris Medik.) for resistance against Ascochyta blight. Ph.D. thesis Dep. Plant Pathol. Univ. Agric., Faisalabad, Pakistan. pp. 157.

Samborski, D.J. and F.R. Forsyth. 1960. Inhibition of rust development on detached wheat leaves by metabolites, antimetabolites and enzyme poisons. Can. J. Bot., 38: 467-476.

Sarwar, N., F.F. Jamil and R. Parveen. 2001. Accumulation of phytoalexins and phenalalnine ammonia lyase in chickpea after inoculation with Ascochyta rabiei and their role in defense mechanism. Pak. J. Bot., 33: 373-382.

Sarwar, N., M.H.Z. Chaudhry, C.I. Haq and F.F. Jamil. 2005. Induction of systemic resistance in chickpea against Fusarium wilt by seed treatment with salicylic acid and BION. Pak. J. Bot., 37: 989-995.

Satya, V.K., S. Gayathiri, R. Bhaskaran, V. Paranidharan and R. Velazhahan. 2007. Induction of systemic resistance to bacterial blight caused by Xanthomonas campestris pv. malvacearum in cotton by leaf extract from a medicinal plant zimmu (Allium sativum L.x Allium cepa L.). Arch. Phytopathol. Plant Prot., 40: 309-322.

Schreiber, K. and D. Desveaux. 2008. Message in a bottle: Chemical biology of induced disease resistance in plants. Plant Pathol. J., 24: 245268.

Sharma, M. and R. Ghosh. 2016. An update on genetic resistance of chickpea to $A$ scochyta blight. Agronomy, 6: 18. https://doi.org/10.3390/ agronomy6010018

Shekari, G. and J. Javanmardi. 2017. Effects of foliar application pure amino acid and amino acid containing fertilizer on broccoli (Brassica oleracea L. var. italica) Transplant. Adv. Crop Sci. Tech., 5: 280.

Singh, D., L.A. Brinkerhoff and G. Guinn. 1971. Effect of alanine on development of Verticillium wilt in cotton cultivars with different levels of resistance, Phytopathology, 61: 881-882.

Singh, U.P and B. Prithiviraj. 1997. Neemazal, a product of neem (Azadirachta indica), induces resistance in pea (Pisum sativum) against Erysiphe pisi. Phys. Mol. Plant Pathol., 51: 181194.

Steel, R.G.O., J.H. Torrie and D. Dickey. 1997. Principles and procedures of statistics. A biometrical approach. $3^{\text {rd }}$ ed. Mc Graw-Hill, New York. U.S.A.

Sun, C., L. Jin, Y. Cai, Y. Huang, X. Zheng and T. Yu. 2019. L-Glutamate treatment enhances disease resistance of tomato fruit by inducing the expression of glutamate receptors and the accumulation of amino acids. Food Chem., 293: 263-270.

Teixeira, W.F., L.H. Soares, E.B. Fagan, S. da Costa Mello, K. Reichardt and D. Dourado-Neto. 2019. Amino acids as stress reducers in soybean plant growth under different water-deficit conditions. J. Plant Growth Regul., pp. 1-15. https://doi.org/10.1007/s00344-019-10032-z

Tivoli B., A. Baranger, C.M. Avila, S. Banniza, M. Barbetti and W. Chen. 2006. Screening techniques and sources of resistance to foliar diseases caused by major necrotrophic fungi in grain legumes. Euphytica. 147: 223-253.

Ton, J., C.J.M. Pieterse and L.C. van Loon. 1999. Identification of alocus in Arabidopsis controlling both the expression of a rhizobacteria-mediated induce systemic resistance (ISR) and basal resistance against Pseudomonas syringae pv tomato. Mol. Plant Microb. Int., 12: 911-918.

Tuzun, S. and A. Somanchi. 2006. The possible role of $\mathrm{PR}$ proteins in multigenic and induced systemic resistance. In: Multigenic and induced 
systemic resistance in plants. Tuzun, S. and Bent, E. (ed.). Springer Publisher, Germany. pp 112-142.

Vafaei, S.H., S. Rezaee, A.A. Moghadam and H.R. Zamanizadeh. 2015. Virulence diversity of Ascochyta rabiei the causal agent of Ascochyta blight of chickpea in the western provinces of Iran. Arch. Phytopathol. Plant Prot., 48: 921930.

van Andel, O.M., 1958. Investigations on plant chemotherapy. II. Influence of amino acids on the relation plant-pathogen. Tijdschr. Plantenzieklen, 64: 307-27.

Van Andel, O.M., 1967. Amino acids and plant diseases. Ann. Rev. Phytopathol., 4: 349-368.

Van Wees, S.C.M., C.M.J. Pieterse, A. Trijissenaar, Y.A.M. Van't Westende, F. Hartog and L. van Loon. 1997. Differential induction of systemic resistance in Arabidopsis by biocontrol bacteria. Mol. Plant Microb. Int., 10: 716-724.
Vir, S. and J.S. Grewal. 1994. Changes in phenolic contents of gram plant induced by Ascochyta rabiei infection. Indian Phytopathol., 27: 355360.

Walters, D. D. Walsh, A. Newton and G. Lyon. 2005. induce resistance for plant disease control: Maximing the efficacy of resistance elicitors. Phytopathology, 95: 1368-1373.

Walters, D.R. and J.M. Fountaine. 2009. Practical application of induced resistance to plant diseases: an appraisal of effectiveness under field conditions. J. Agric. Sci., pp. 1-13. https:// doi.org/10.1017/S0021859609008806

Yakhin, O.I., A.L. Aleksandr, A.Y. Ildus and H.B. Patrick. 2017. Biostimulants in plant science: A global perspective. Front. Plant Sci., 7: 2049.

Zhou, Z., I. Bar, P.T. Sambasivam and R. Ford. 2019. Determination of the key resistance gene analogs involved in ascochyta rabiei recognition in chickpea. Front. Plant Sci., 10: 644. 